\title{
Electronic Structure, Nonlinear Optical Properties, and Vibrational Analysis of Gemifloxacin by Density Functional Theory
}

\author{
Shamoon Ahmad Siddiqui, ${ }^{1}$ Tabish Rasheed, ${ }^{2}$ Mohd Faisal, ${ }^{1}$ \\ Anoop Kumar Pandey, ${ }^{3}$ and Sher Bahadar Khan ${ }^{4}$ \\ ${ }^{1}$ Centre for Advanced Materials and Nanoengineering, Najran University, P.O. Box 1988, \\ Najran 11001, Saudi Arabia \\ ${ }^{2}$ Department of Applied Sciences, School of Engineering and Technology, Sharda University, \\ Plot No. 32-34, Knowledge Park III, Greater Noida 201306, India \\ ${ }^{3}$ Department of Physics, University of Lucknow, Lucknow 226001, India \\ ${ }^{4}$ Center of Excellence for Advanced Materials Research and Chemistry Department, Faculty of Science, \\ King Abdulaziz University, P.O. Box 80203, Jeddah 21589, Saudi Arabia
}

Correspondence should be addressed to Shamoon Ahmad Siddiqui, shamoonasiddiqui@gmail.com

Copyright ( $) 2012$ Shamoon Ahmad Siddiqui et al. This is an open access article distributed under the Creative Commons Attribution License, which permits unrestricted use, distribution, and reproduction in any medium, provided the original work is properly cited.

\begin{abstract}
The non-linear optical properties of gemifloxacin $\left(\mathrm{C}_{18} \mathrm{H}_{20} \mathrm{FN}_{5} \mathrm{O}_{4}\right)$ have been examined using density functional theory (DFT). The molecular HOMO, LUMO composition, their respective energy gaps, MESP contours/surfaces have also been drawn to explain the activity of gemifloxacin. The equilibrium geometries and harmonic frequencies of title molecule was determined and analyzed at DFT/B3LYP level employing the 6-31G(d,p) basis set. The skeleton of both the optimized molecules is non-planar. In general, a good agreement between experimental and calculated normal modes of vibrations has been observed.
\end{abstract}

Keywords: Nonlinear optical properties, polarizability, first static hyperpolarizability, MESP, vibrational spectra

\section{Introduction}

Gemifloxacin (7-[(4E)-3-(aminomethyl)-4-methoxyiminopyrrolidin-1-yl]-1-cyclopropyl-6-fluoro-4-oxo1,8-naphthyridine-3-carboxylic acid) is an oral broad-spectrum quinolone antibacterial agent widely used in the treatment of acute bacterial exacerbation of chronic bronchitis and mild-to-moderate pneumonia [1-3]. Gemifloxacin acts by inhibiting DNA synthesis through the inhibition of both DNA gyrase and topoisomerase IV enzymes, which are essential for bacterial growth. Notably this drug has about 100 times higher affinity for bacterial DNA gyrase than for mammalian ones. Gemifloxacin is a broad-spectrum antibiotic that is highly active against both Gram-positive and Gram-negative bacteria 


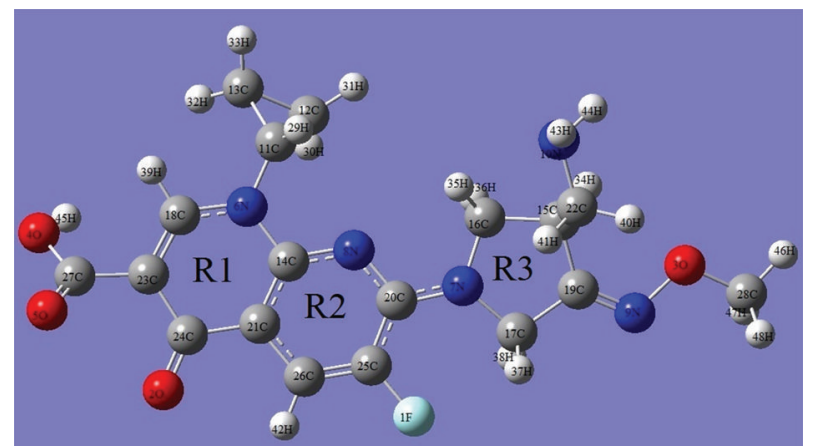

Figure 1: Molecular structure and numbering scheme of gemifloxacin.

$[4,5]$. Gemifloxacin is globally used for the treatment of bacterial infection caused by susceptible strains like S. pneumoniae, H. influenzae, H. parainfluenzae, or M. catarrhalis, S. pneumoniae (including multidrug-resistant strains (MDRSP)), M. pneumoniae, C. pneumonia; K. pneumoniae. Gemifloxacin rapidly absorbed from the gastrointestinal tract and the absolute bioavailability averages approximately $71 \%$. Gemifloxacin is metabolized to a certain extent by the liver. All metabolites formed are minor $(<10 \%$ of the administered oral dose); the principal ones are $\mathrm{N}$-acetyl gemifloxacin, the E-isomer of gemifloxacin and the carbamyl glucuronide of gemifloxacin [6,7].

The aim of the present communication is to investigate the molecular structure, vibrational spectra, and energetic data analysis of the molecule under study, in gas phase, due to biological and pharmaceutical importance of the title molecule. The structure and the ground-state energy of the drug under investigation have been analyzed employing density functional theory with B3LYP method. In order to obtain a more complete description of molecular vibration, vibrational frequency calculation has been carried out. The vibrational analysis also provides the detailed information about the intramolecular vibrations in the fingerprint region. The reported optimized geometries, molecular properties such as equilibrium energy, HOMO-LUMO gap, dipole moment, polarizability as well as first static hyperpolarizability components along with the electrostatic potential contours and surfaces have also been used to understand the activity of the molecules.

\section{Experimental: Structure and Spectra}

The fourier transform infrared spectrum was recorded with FT-IR Perkin Elmer spectrometer in $\mathrm{KBr}$ dispersion in the range of 400 to $4000 \mathrm{~cm}^{-1}$. The optical properties of the gemifloxacin were examined using UV-visible spectrophotometer at room temperature. UV-visible spectrum was recorded in the range of 190-800 nm with Perkin Elmer-Lambda 950-UV-visible spectrometer. To measure the UVvisible absorption, the gemifloxacin particles were dispersed in distilled DI water and measured. The model molecular structure of gemifloxacin has been given in Figure 1. The experimental and calculated FT-IR spectra is given in Figure 2, and the experimental UV-visible spectrum is given in Figure 3. 


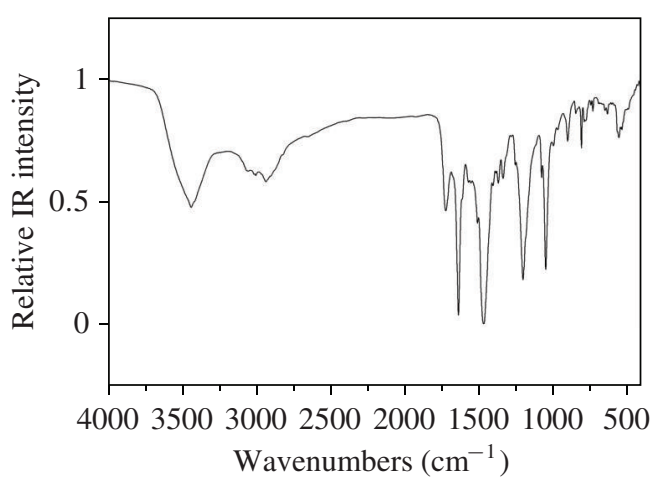

(a)

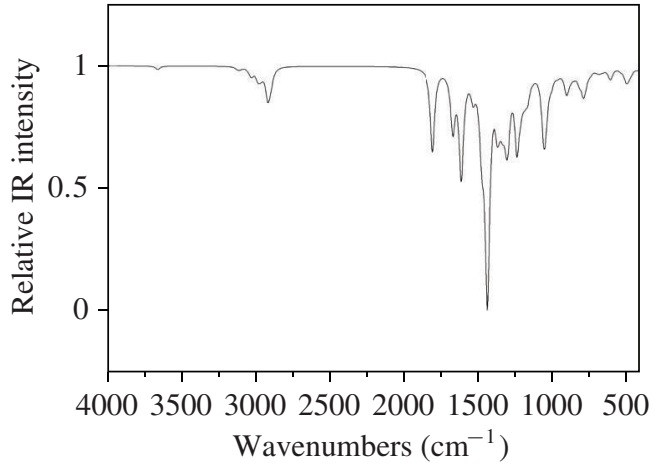

(b)

Figure 2: Comparison of normalized IR spectra: (a) experimental (FTIR) and (b) scaled simulated spectrum obtained by using DFT (scaling factor $\times 0.96$ ) harmonic calculations for gemifloxacin.

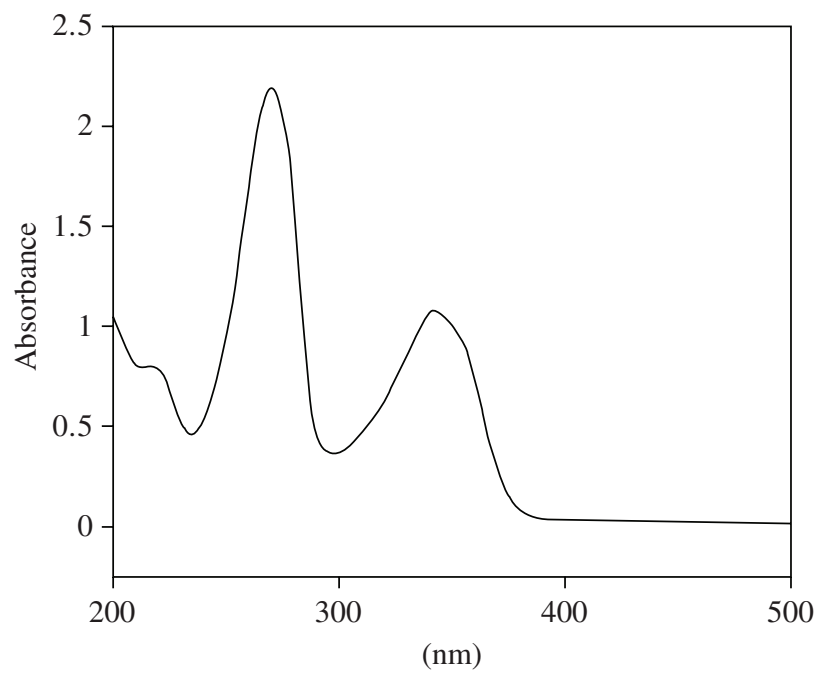

Figure 3: UV-visible spectrum of gemifloxacin.

\section{Computational Details}

In the present communication the density functional theory (DFT) [8] has been employed using Becke's three-parameter hybrid exchange functionals [9] with the Lee-Yang-Parr correlation functionals [10, 11] to optimize the molecular structure and to calculate the electronic structure properties of the drug molecule. The Gaussian 03W program [12] was used to calculate the vibrational spectra, dipole moment $(\mu)$, polarizability $(\alpha)$, and the first static hyperpolarizability $(\beta)$ of the title molecule, based on the finite field approach. The vibrational frequencies are calculated and scaled down by the appropriate factor [13, 14]. The vibrational wavenumber assignments and PED calculation have been carried out by combining the result of the Gauss View 4.1 and the VEDA program $[15,16]$ with symmetry considerations. 


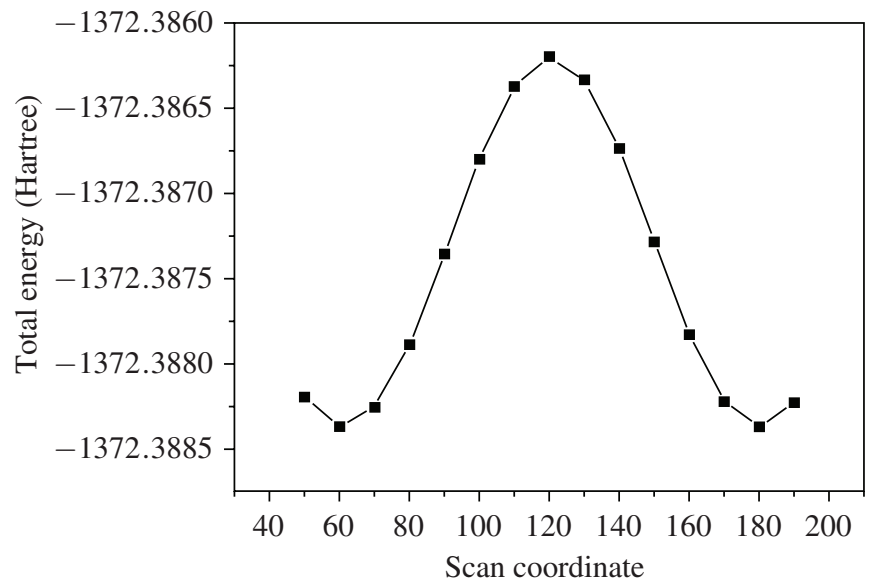

Figure 4: PES scan for dihedral angle $\mathrm{N}_{9}-\mathrm{O}_{3}-\mathrm{C}_{28}-\mathrm{H}_{46}$ at B3LYP/6-31G(d,p).

The comparative experimental and calculated FTIR spectrum plotted using the pure Lorentzian band shape is shown in Figure 2.

\section{Result and Discussion}

\subsection{Analysis of Conformers of Gemifloxacin}

Theoretical calculations for conformers of gemifloxacin were carried out using the B3LYP/6-31G(d,p) method. The plots of the potential energy surface (PES) scans for this molecule are shown in Figures 4 and 5. The dihedral angles $\mathrm{N}_{9}-\mathrm{O}_{3}-\mathrm{C}_{28}-\mathrm{H}_{46}$ and $\mathrm{C}_{18}-\mathrm{C}_{23}-\mathrm{C}_{27}-\mathrm{O}_{5}$ are the relevant coordinates for conformational calculations within the molecule. In these calculations, all the geometrical parameters were simultaneously relaxed during the calculations while the dihedral angles were varied in steps of $10^{\circ}, 20^{\circ}, 30^{\circ}, \ldots, 360^{\circ}$. The global minimum energy structure was obtained at $-179.821^{\circ}$ and $-132.892^{\circ}$ for the dihedral angles $\mathrm{N}_{9}-\mathrm{O}_{3}-\mathrm{C}_{28}-\mathrm{H}_{46}$ and $\mathrm{C}_{18}-\mathrm{C}_{23}-\mathrm{C}_{27}-\mathrm{O}_{5}$, respectively. The corresponding minimum energy for both PES scans was -1372.3884 Hartree, which implies that the obtained structure was a global minimum. This structure is shown in Figure 1 and was used for performing frequency calculations.

\subsection{Molecular Geometry Optimization}

The equilibrium geometry optimization of lowest energy conformer has been achieved by energy minimization. The optimized geometry of the molecule under study is confirmed to be located at the global minima on PES, as the calculated vibrational spectrum contains no imaginary wavenumber. The given molecule has three rings. Out of these two are six membered and one five membered. Ring R1 and $\mathrm{R} 2$ are in a plane while ring R3 deviates from the given plane due to two bulky groups, one attached at $6 \mathrm{~N}$ of ring $\mathrm{R} 1$ and the other attached at $19 \mathrm{C}$. The optimized bond length of $\mathrm{C}-\mathrm{C}$ in six-membered pyridine ring $\mathrm{R} 1$ ranges between $1.367 \AA$ and $1.475 \AA$, while, for another pyridine ring $\mathrm{R} 2$, this ranges 


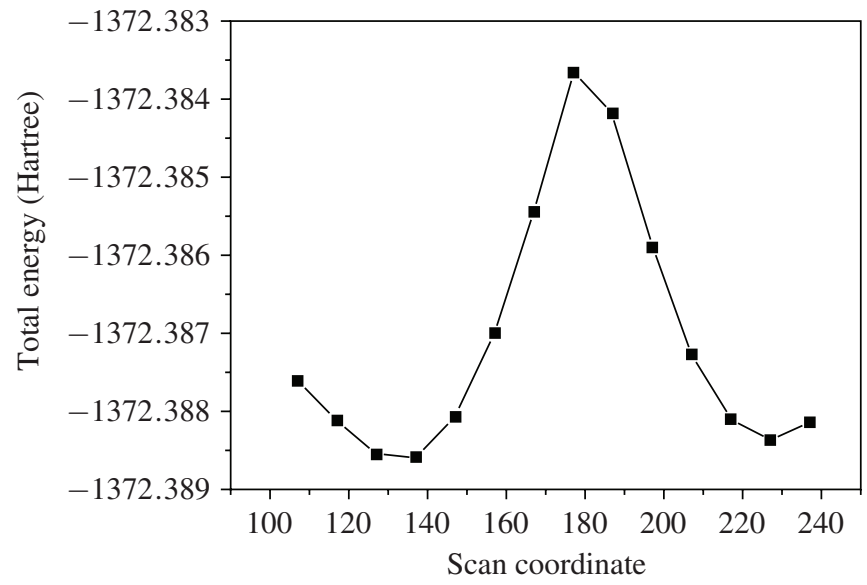

Figure 5: PES scan for dihedral angle $\mathrm{C}_{18}-\mathrm{C}_{23}-\mathrm{C}_{27}-\mathrm{O}_{5}$ at B3LYP/6-31G(d,p).

between $1.366 \AA$ and $1.401 \AA$. For five-membered pyrrole ring R3, C-C bond lengths are quite high and range between $1.510 \AA$ and $1.536 \AA$. The optimized value of $\mathrm{C} 23-\mathrm{C} 27$ bond length adjacent to pyridine ring $\mathrm{R} 1$ is found to be $1.496 \AA$, which is also high in comparison to the $\mathrm{C}-\mathrm{C}$ bond length in $\mathrm{R} 1$. The optimized value of $\mathrm{C} 15-\mathrm{C} 22$ bond length adjacent to pyrrole ring R3 is found to be $1.546 \AA$, which is also high in comparison to the $\mathrm{C}-\mathrm{C}$ bond length in $\mathrm{R} 3$. Another important $\mathrm{C}-\mathrm{C}$ bond length in cyclopropane attached to pyridine ring $\mathrm{R} 1$ is found in the range $1.501 \AA-1.508 \AA$. The optimized $\mathrm{C}-\mathrm{N}$ bond lengths in pyridine ring R1 are found to be $1.367 \AA$ and $1.401 \AA$, while, in pyridine ring $\mathrm{R} 2$, the optimized C-N bond lengths are found to be $1.337 \AA$ and $1.341 \AA$. On the other hand the optimized $\mathrm{C}-\mathrm{N}$ bond lengths in pyrrole ring R3 are calculated as $1.473 \AA$ and $1.469 \AA$, which is quite high in comparison to $\mathrm{C}-\mathrm{N}$ bond length in both pyridine ring $\mathrm{R} 1$ and $\mathrm{R} 2$ because $\mathrm{C}-\mathrm{N}$ bond in $\mathrm{R} 2$ is double bond while $\mathrm{C}-\mathrm{N}$ bond in ring $\mathrm{R} 1$ has just double bond character due to delocalization of lone pair electrons of nitrogen in R1. C11-N6 bond length adjacent to ring R1 is found to be $1.451 \AA$, while C20-N7 bond length between ring R2 and R3 is calculated as $1.365 \AA$, which is quite small in comparison to C11-N6 bond length. The length of $\mathrm{C} 19=\mathrm{N} 9$ bond adjacent to ring R3 is found to be $1.276 \AA$, while $\mathrm{C} 22-\mathrm{N} 10$ bond length is found to be $1.465 \AA$. The length of C28-O3 bond adjacent to pyrrole ring R3 is found to be $1.425 \AA$. Values of all the bond angles are given in Table 1, and all are in accordance with previous experimental and theoretical studies on different biomolecules [17-19].

In five-membered ring, torsional strain also arises from the fact that, as the lateral distance between the bonds on two adjacent carbon atoms decreases, the repulsive interaction between the electrons of the bonds increases which cause decrease in bond angle. The double bond is $\mathrm{sp}^{2}$ hybridized and forms bonds with bond angles of about $120^{\circ}$. In such cases the unsaturated double bond has two electron pairs, one of the sigma bond and the other of the pi bond. Repulsion by these two electron pairs, the other bond pair is greater than that between two single bond pairs. This leads to deviations from exact trigonal geometry. The same is the reason for R1 and R2 which shows lower bond angles as compared to true trigonal geometry. 
Table 1: Optimized geometrical parameters of gemifloxacin, bond length $(\AA)$, and bond angle $\left(^{\circ}\right)$.

\begin{tabular}{|c|c|c|c|c|}
\hline S. no. & Optimized parameters & Bond length & Optimized parameters & Bond angle \\
\hline 1 & $\mathrm{~F} 1-\mathrm{C} 25$ & 1.3568 & N9-O3-C28 & 108.7776 \\
\hline 2 & $\mathrm{O} 2=\mathrm{C} 24$ & 1.2292 & C27-O4-H45 & 108.8845 \\
\hline 3 & O3-N9 & 1.4063 & C11-N6-C14 & 119.7248 \\
\hline 4 & $\mathrm{O} 3-\mathrm{C} 28$ & 1.425 & C11-N6-C18 & 120.7158 \\
\hline 5 & $\mathrm{O} 4-\mathrm{C} 27$ & 1.3734 & C14-N6-C18 & 119.1417 \\
\hline 6 & $\mathrm{O} 4-\mathrm{H} 45$ & 0.9675 & C16-N7-C17 & 112.2795 \\
\hline 7 & $\mathrm{O} 5=\mathrm{C} 27$ & 1.2025 & C16-N7-C20 & 120.2429 \\
\hline 8 & N6-C11 & 1.4508 & C17-N7-C20 & 125.3726 \\
\hline 9 & N6-C14 & 1.4014 & C14-N8-C20 & 119.5509 \\
\hline 10 & N6-C18 & 1.3673 & O3-N9-C19 & 111.185 \\
\hline 11 & N7-C16 & 1.4734 & C22-N10-H43 & 109.9774 \\
\hline 12 & N7-C17 & 1.4695 & C22-N10-H44 & 109.7683 \\
\hline 13 & N7-C20 & 1.3647 & H43-N10-H44 & 106.2508 \\
\hline 14 & N8-C14 & 1.3369 & N6-C11-C12 & 119.8908 \\
\hline 15 & N8-C20 & 1.3412 & N6-C11-C13 & 119.6133 \\
\hline 16 & N9-C19 & 1.2761 & N6-C11-H29 & 113.1169 \\
\hline 17 & N10-C22 & 1.4655 & C12-C11-H29 & 116.832 \\
\hline 18 & N10-H43 & 1.0166 & C13-C11-H29 & 117.5714 \\
\hline 19 & N10-H44 & 1.018 & C11-C12-H30 & 117.0507 \\
\hline 20 & $\mathrm{C} 11-\mathrm{C} 12$ & 1.5012 & C11-C12-H31 & 117.4329 \\
\hline 21 & C11-C13 & 1.5077 & C13-C12-H30 & 117.2739 \\
\hline 22 & $\mathrm{C} 11-\mathrm{H} 29$ & 1.0867 & C13-C12-H31 & 119.4588 \\
\hline 23 & C12-C13 & 1.5081 & H30-C12-H31 & 114.7379 \\
\hline 24 & C12-H30 & 1.0845 & C11-C13-H32 & 118.7106 \\
\hline 25 & C12-H31 & 1.0847 & C11-C13-H33 & 117.2653 \\
\hline 26 & C13-H32 & 1.0853 & C12-C13-H32 & 117.1928 \\
\hline 27 & C13-H33 & 1.0851 & C12-C13-H33 & 119.3677 \\
\hline 28 & $\mathrm{C} 14-\mathrm{C} 21$ & 1.4051 & H32-C13-H33 & 114.1386 \\
\hline 29 & C15-C16 & 1.5356 & N6-C14-N8 & 116.6219 \\
\hline 30 & C15-C19 & 1.5101 & N6-C14-C21 & 119.0267 \\
\hline 31 & $\mathrm{C} 15-\mathrm{C} 22$ & 1.546 & N8-C14-C21 & 124.3514 \\
\hline 32 & C15-H34 & 1.095 & C16-C15-C19 & 103.1176 \\
\hline 33 & C16-H35 & 1.0901 & C16-C15-C22 & 112.5205 \\
\hline 34 & C16-H36 & 1.0988 & C16-C15-H34 & 111.7457 \\
\hline 35 & C17-C19 & 1.5139 & C19-C15-C22 & 111.514 \\
\hline 36 & C17-H37 & 1.093 & C19-C15-H34 & 109.6012 \\
\hline 37 & C17-H38 & 1.0974 & C22-C15-H34 & 108.2916 \\
\hline 38 & $\mathrm{C} 18-\mathrm{C} 23$ & 1.3673 & N7-C16-C15 & 104.2976 \\
\hline
\end{tabular}


Table 1: Continued.

\begin{tabular}{lcccc}
\hline S. no. & Optimized parameters & Bond length & Optimized parameters & Bond angle \\
\hline 39 & C18-H39 & 1.084 & N7-C16-H35 & 110.6862 \\
40 & C20-C25 & 1.428 & N7-C16-H36 & 110.474 \\
41 & C21-C24 & 1.4753 & C15-C16-H35 & 111.9643 \\
42 & $\mathrm{C} 21-\mathrm{C} 26$ & 1.4077 & $\mathrm{C} 15-\mathrm{C} 16-\mathrm{H} 36$ & 111.7943 \\
43 & $\mathrm{C} 22-\mathrm{H} 40$ & 1.0995 & $\mathrm{H} 35-\mathrm{C} 16-\mathrm{H} 36$ & 107.6519 \\
44 & $\mathrm{C} 22-\mathrm{H} 41$ & 1.0964 & $\mathrm{~N} 7-\mathrm{C} 17-\mathrm{C} 19$ & 102.8584 \\
45 & $\mathrm{C} 23-\mathrm{C} 24$ & 1.4728 & $\mathrm{~N} 7-\mathrm{C} 17-\mathrm{H} 37$ & 111.4483 \\
46 & $\mathrm{C} 23-\mathrm{C} 27$ & 1.4958 & $\mathrm{~N} 7-\mathrm{C} 17-\mathrm{H} 38$ & 112.38 \\
47 & $\mathrm{C} 25-\mathrm{C} 26$ & 1.3663 & $\mathrm{C} 19-\mathrm{C} 17-\mathrm{H} 37$ & 111.6618 \\
48 & $\mathrm{C} 26-\mathrm{H} 42$ & 1.0846 & $\mathrm{C} 19-\mathrm{C} 17-\mathrm{H} 38$ & 111.1651 \\
49 & $\mathrm{C} 28-\mathrm{H} 46$ & 1.0921 & $\mathrm{H} 37-\mathrm{C} 17-\mathrm{H} 38$ & 107.3873 \\
50 & $\mathrm{C} 28-\mathrm{H} 47$ & 1.0954 & $\mathrm{~N} 6-\mathrm{C} 18-\mathrm{C} 23$ & 124.8211 \\
51 & $\mathrm{C} 28-\mathrm{H} 48$ & 1.0953 & $\mathrm{~N} 6-\mathrm{C} 18-\mathrm{H} 39$ & 114.179 \\
\hline
\end{tabular}

Table 2: Calculated parameters using TDDFT/B3LYP/6-31G(d,p) for gemifloxacin.

\begin{tabular}{|c|c|c|c|c|c|}
\hline \multirow{2}{*}{ Excitation } & \multirow{2}{*}{$\begin{array}{l}\text { CI expansion } \\
\text { coefficient }\end{array}$} & \multicolumn{2}{|c|}{ Wavelength (nm) } & \multirow{2}{*}{$\begin{array}{l}\text { Oscillator } \\
\text { strength }(f)\end{array}$} & \multirow{2}{*}{ Energy $(\mathrm{eV})$} \\
\hline & & Calculated & Experimental & & \\
\hline Excited state 1 & & 325.93 & 342 & 0.3149 & 3.8040 \\
\hline $102 \rightarrow 103$ & 0.63798 & & & & \\
\hline $102 \rightarrow 104$ & 0.14530 & & & & \\
\hline Excited state 2 & & 309.18 & & 0.0090 & 4.0101 \\
\hline $99 \rightarrow 103$ & 0.65753 & & & & \\
\hline $100 \rightarrow 103$ & -0.12556 & & & & \\
\hline Excited state 3 & & 295.49 & 270 & 0.0394 & 4.1959 \\
\hline $100 \rightarrow 103$ & -0.29490 & & & & \\
\hline $101 \rightarrow 103$ & 0.31447 & & & & \\
\hline $102 \rightarrow 104$ & 0.50647 & & & & \\
\hline
\end{tabular}

\subsection{Electronic Spectra of Gemifloxacin}

On the basis of fully optimized ground-state structure, TDDFT/B3LYP/6-31G(d,p) calculations have been used to determine the low-lying excited states of gemifloxacin. The calculated results involving the vertical excitation energies, oscillator strength $(f)$, and wavelength are carried out using the Gaussian $03 \mathrm{~W}$ program and compared with measured experimental wavelength. Electronic transitions determined from excited-state calculations are listed in Table 2 for the three lowest energy transitions of the molecule. TD-DFT calculation predicts two intense electronic transition at $3.8040 \mathrm{eV}(325.93 \mathrm{~nm})$ and $4.1959 \mathrm{eV}$ (295.49) with oscillator strengths of 0.3149 and 0.0394 , respectively, in good agreement with the measured experimental data ( $\exp =270 \mathrm{~nm}$ and $342 \mathrm{~nm}$ ) as shown in Figure 3. 
Table 3: Calculated values of polarizability and hyperpolarizability using DFT/6-31G(d,p) for gemifloxacin.

\begin{tabular}{lcccc}
\hline S. no & $\begin{array}{c}\text { Polarizability } \\
\text { parameters }\end{array}$ & Value (e.s.u) & $\begin{array}{c}\text { Hyperpolarizability } \\
\text { parameters }\end{array}$ & $\begin{array}{c}\text { Value } \\
(\mathrm{e} . \mathrm{s.u})\end{array}$ \\
\hline 1 & $\alpha_{x x}$ & 155.517 & $\beta_{x x x}$ & 588.2079 \\
2 & $\alpha_{x y}$ & 7.2473627, & $\beta_{x x y}$ & 157.9636 \\
3 & $\alpha_{y y}$ & 239.2203429 & $\beta_{x y y}$ & 38.9723 \\
4 & $\alpha_{y z}$ & -13.711457 & $\beta_{y y y}$ & 26.2387 \\
5 & $\alpha_{z z}$ & 140.0071631 & $\beta_{z z z}$ & 0.8472 \\
6 & $\alpha_{z x}$ & -4.3056718 & $\beta_{x x z}$ & -1.4496 \\
7 & $A$ & 122.9957 & $\beta_{x z z}$ & 24.0212 \\
8 & & & $\beta_{y z z}$ & 7.9028 \\
9 & & & $\beta_{y y z}$ & 9.3606 \\
10 & & & $\beta_{x y z}$ & 8.7427 \\
11 & & & $\beta_{\text {total }}$ & 94.3118 \\
\hline
\end{tabular}

\subsection{Dipole Moment, Polarizability, and First Static Hyperpolarizability}

According to Buckingham's definitions [20], DFT has also been used to calculate the dipole moment $(\mu)$, polarizability $(\alpha)$, and the first static hyperpolarizability $(\beta)$. The total intrinsic hyperpolarizability $\beta_{\text {TOTAL }}[21]$ and a component of the first hyperpolarizability along the direction of the dipole moment are represented by $\beta[21,22]$.

The $\beta$ components of the Gaussian output are reported in atomic units, where 1 a.u. $=8.3693 *$ $10^{-33}$ e.s.u..

Table 3 clearly shows that molecule has major component of polarizability along axial direction; however, perpendicular components of polarizability have negligible contribution. Thus the polarization ellipsoid nearly planar is stretched along $Y$ axis and contracted along $Z$ axis. Thus dipole formed along $X Y Z$ axis and less stretched along perpendicular direction. The plane contains $X X$ and $X Y$ having major part of hyperpolarizability. It means ellipsoids flattered along this plane. This means that this molecule is optically reactive in $X$ direction.

\subsection{Electronic Properties}

HOMOs and LUMOs determine the way the molecule interacts with other species. The frontier orbital gap helps characterize the chemical reactivity of molecule. A molecule which have more orbital gap is more less polarized and less chemically reactive [23]. According to the present DFT calculations, the frontier orbital gap in case of given molecule is $4.30 \mathrm{eV}$. The $3 \mathrm{D}$ and $2 \mathrm{D}$ plots of the HOMO, LUMO, and electrostatic potential for the molecule are shown in Figures (6-8). HOMO is located at ring R1 and R2, however, half R3 and F atom part of pentagon ring. If we see 2D plot of HOMO (Figure 6) a negative equipotential concentric line appears around $\mathrm{N}$ atom (ring R1) and $\mathrm{F}$ atom (adjacent to ring R2). However, a surface of positive line is closely concentrated around $\mathrm{O}$ atom adjacent to ring $\mathrm{R} 1$. It clearly 


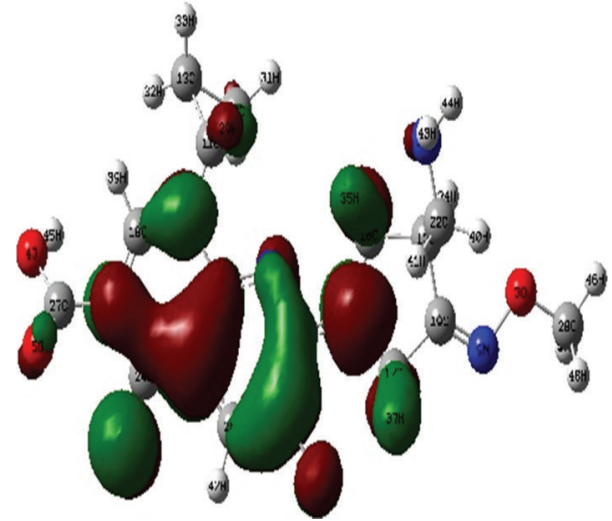

(a)

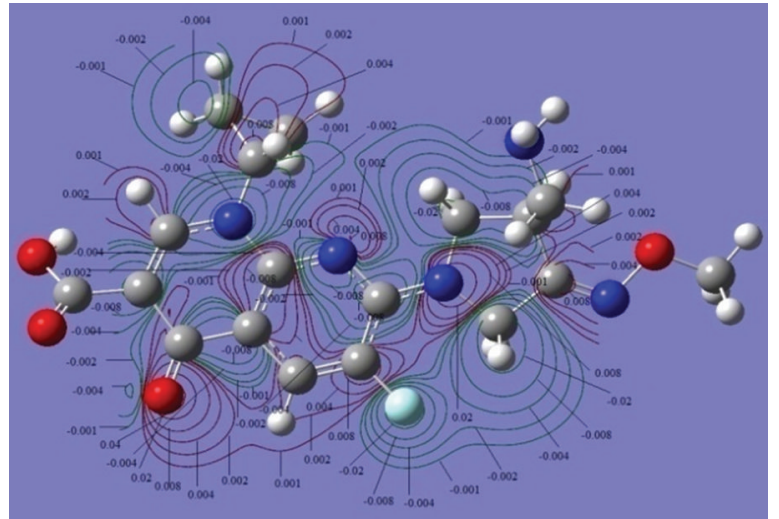

(b)

Figure 6: 3D and 2D plots of highest occupied molecular orbital.

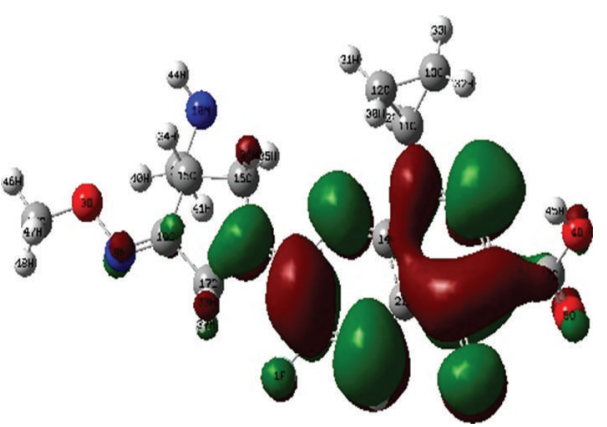

(a)

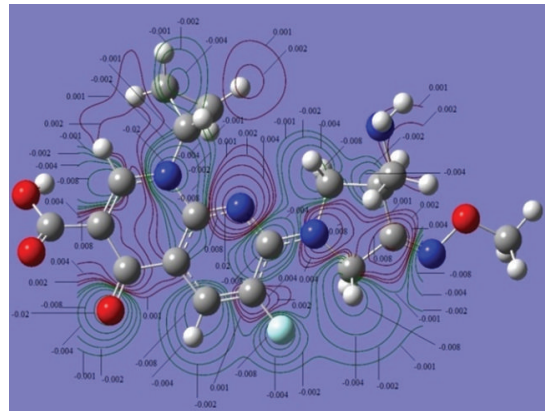

(b)

Figure 7: 3D and 2D plots of lowest unoccupied molecular orbital.

indicates that delocalized electrons are confined at negative region of given molecule, however, shifted from positive part. This type of delocalized electron takes part in reaction and behaves as active part for binding to the receptor. LUMOs are located (Figure 7) at same place as HOMOs, except to those two carbon which are adjoint to ring R1 and R2. In the case of given molecule, the electronegative region (red) is towards the outer part and near the oxygen which is adjacent to ring $\mathrm{R} 1$, and moderate positive region (green) is located nearly over whole molecule.

The importance of MESP lies in the fact that it simultaneously displays size as well as shape and with the help of colour grading (shown in Figure 8) defined positive, negative, and neutral electrostatic potential regions, which are very useful in investigation of molecular structure with its physiochemical property relationship [24-28]. As we see from 2D molecular electrostatic potential plot (Figure 8), negative equipotential surface lines are passing near to $\mathrm{O}$ atom which is adjacent to ring $\mathrm{R} 1$, and other negative potential regions are found near to $\mathrm{N}$ atom of ring $\mathrm{R} 2$ (where negative lines closely form a concentric circle). Negative potential surface line near to $\mathrm{O}$ atom is passing through $\mathrm{F}$ atom. This indicates that it is suitable place for nucleophilic substitution reaction. The energy equal to the shielded 


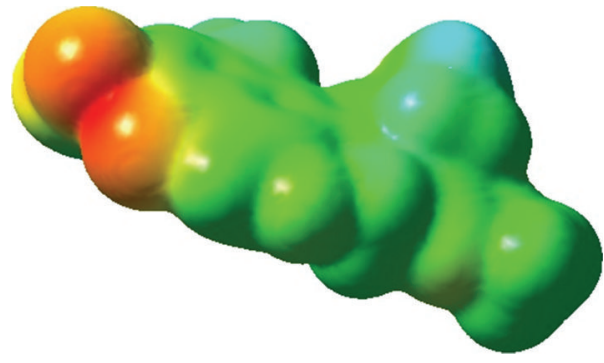

(a)

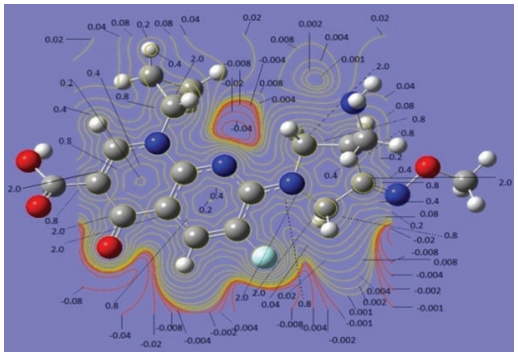

(b)

Figure 8: $3 \mathrm{D}$ and 2D plots of molecular electrostatic potential.

PES is required for any substitution reaction near the oxygen. The electronegative lines (between -0.08 .u. and -0.04.u.) form a closed contour which clearly indicates that the total flux passing in between these curves is not equal to zero. It generates a negative electric field region near the oxygen atom which opposes the electrophilic substitution. The molecule acts as a dipole in which the area near the oxygen atom acts as the negative pole (better site for positive radicals in human bodies), however, the remaining part of the molecule is suitable for electrophilic substitution reaction. Out of these, all regions are surrounded by the positive potential surface line over whole molecule.

\subsection{Vibrational Assignments}

The molecule gemifloxacin contains 48 atoms, and it has 138 normal modes of vibration. All the 138 fundamental vibrations are IR active. The harmonic-vibrational frequencies calculated for gemifloxacin and experimental frequencies (FTIR) have been compared in Table 4. Vibrational assignments are based on the observation of the animated modes in GaussView and assignments reported in the literature.

In gemifloxacin, the $\mathrm{C}-\mathrm{H}$ functional group is present at a number of positions. The stretching vibration, $\nu(\mathrm{C}-\mathrm{H})$, is expected to occur in the region $3010-3120 \mathrm{~cm}^{-1}$. The calculated values of the $\nu(\mathrm{C}-\mathrm{H})$ vibration lie within this spectral range. The other important stretching vibration corresponds to the $\mathrm{C}=\mathrm{O}$ moieties at the $\mathrm{C}_{24}$ and $\mathrm{C}_{27}$ positions. The region $1650-1750 \mathrm{~cm}^{-1}$ is generally considered as the double bond stretching region for $\mathrm{C}=\mathrm{O}, \mathrm{C}=\mathrm{C}$, and $\mathrm{C}=\mathrm{N}$ bonds [29-32]. The $\mathrm{C}=\mathrm{O}$ stretching vibration, $\nu(\mathrm{C}=\mathrm{O})$ appears as a prominent mode in the FTIR spectra at $1716 \mathrm{~cm}^{-1}$. Another important stretching vibration in gemifloxacin is the $\mathrm{O}-\mathrm{H}$ stretching vibration. The $\mathrm{O}-\mathrm{H}$ group vibrations are likely to be most sensitive to the environment, so they show pronounced shifts in the spectra of the hydrogen-bonded species. In the subject molecule, the $\nu(\mathrm{O}-\mathrm{H})$ vibration appears at $3439 \mathrm{~cm}^{-1}$ in the FTIR spectrum. The calculated (scaled) and experimental frequencies are deviated by large amount, which may be explained by the presence of hydrogen bondings in the solid sample.

The $-\mathrm{NH}_{2}$, and $-\mathrm{CH}_{2}$, functional groups are important constituents of gemifloxacin and vibrations corresponding to these groups are present in a number of modes. The stretching vibrations of these groups appear in a number of modes. The wagging vibrations $\omega\left(\mathrm{CH}_{2}\right)$ and $\omega\left(\mathrm{NH}_{2}\right)$ are also present in a number of modes. Mode 39 shows a pure $\omega\left(\mathrm{CH}_{2}\right)$ vibration, and there is excellent correspondence between calculated (scaled) and experimental FTIR wavenumber as can been seen in Table 4. 


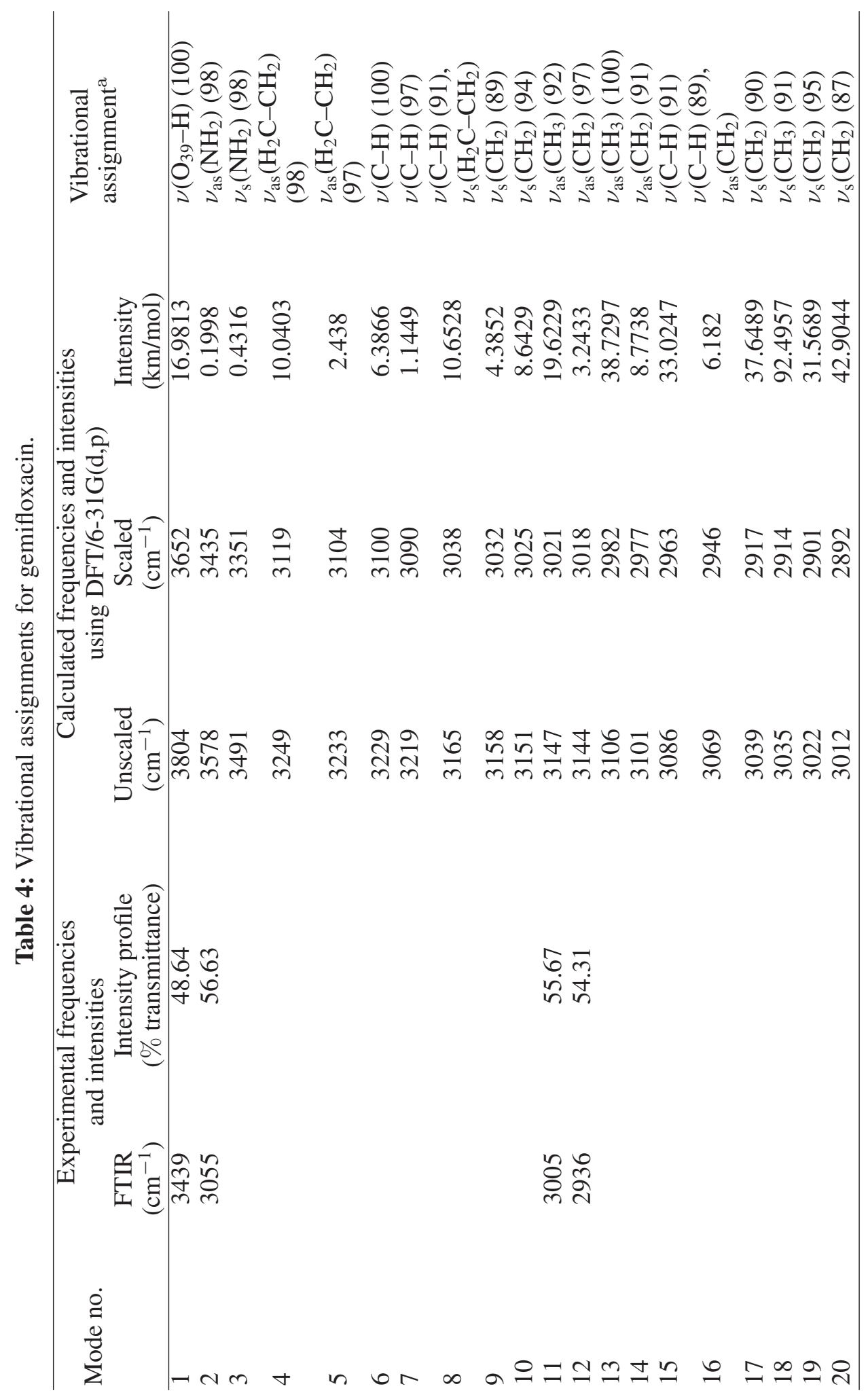




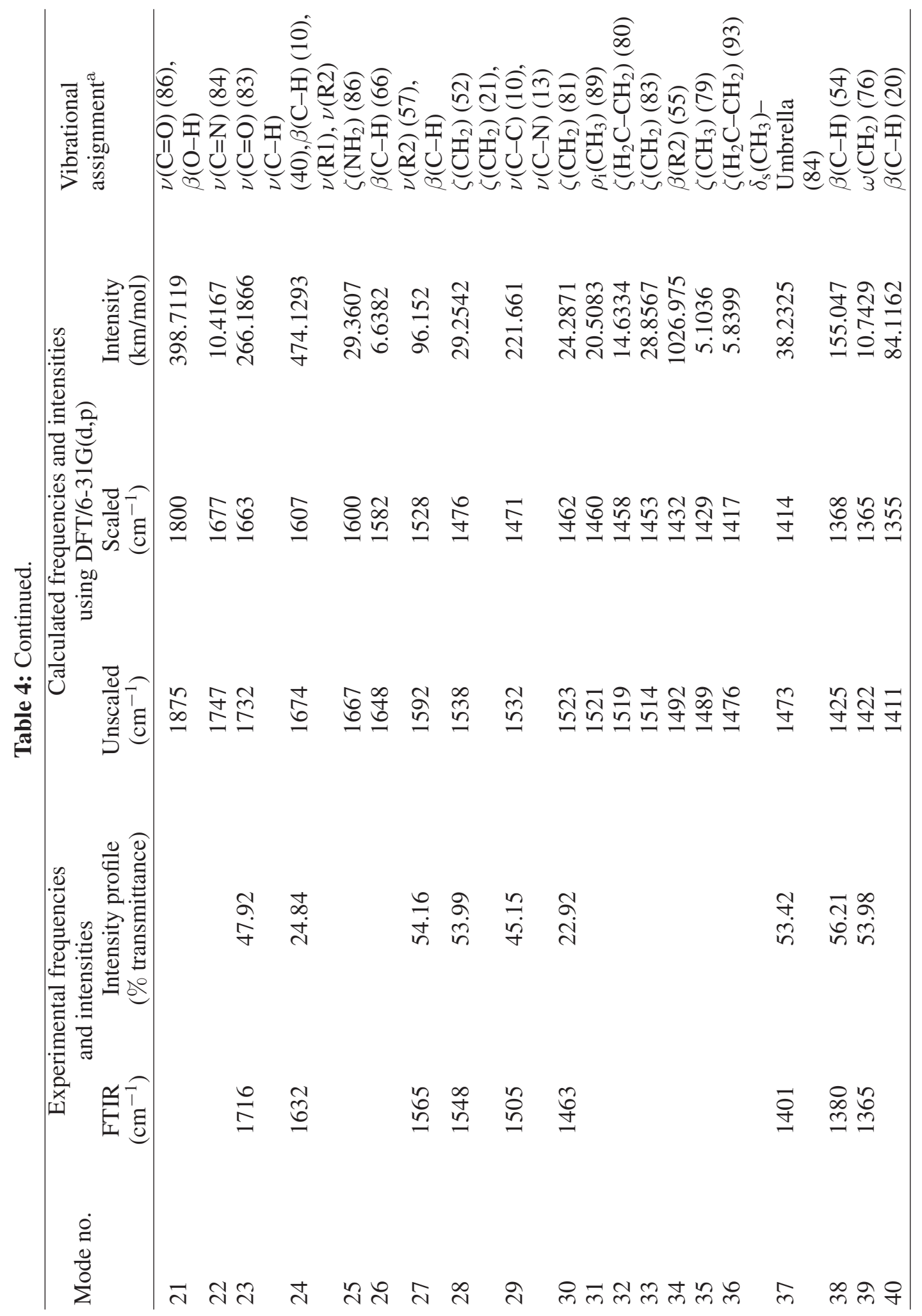




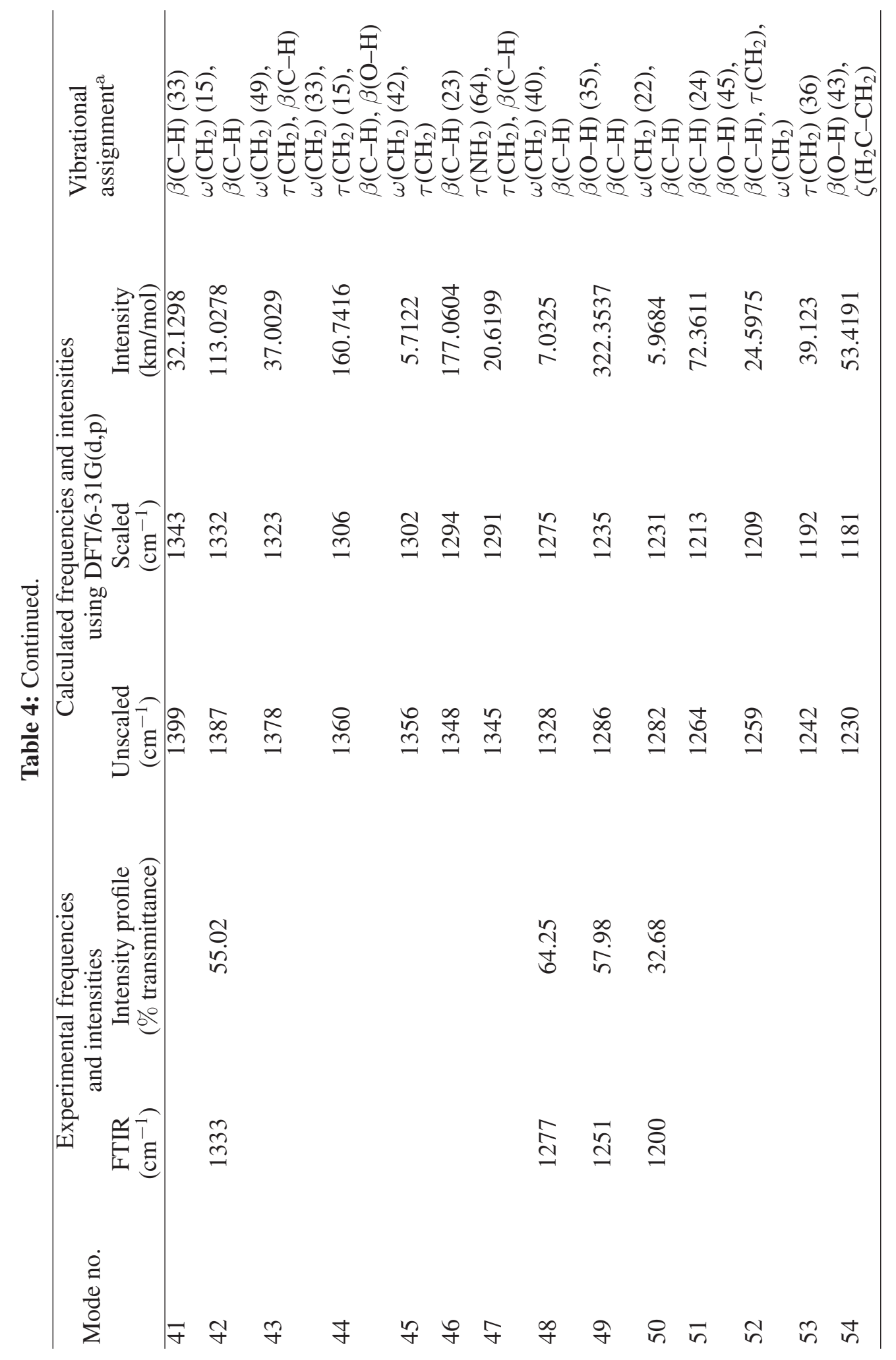




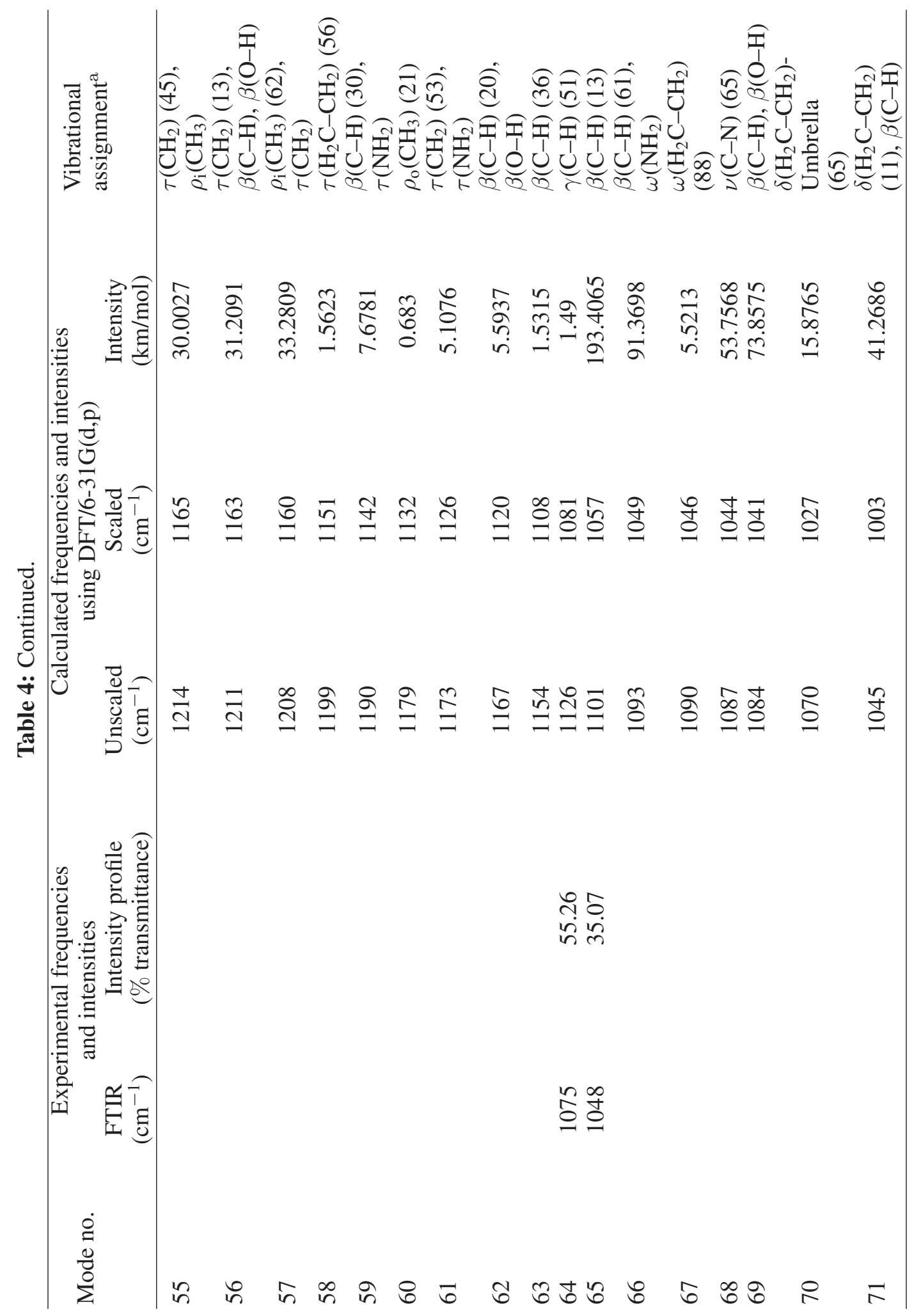




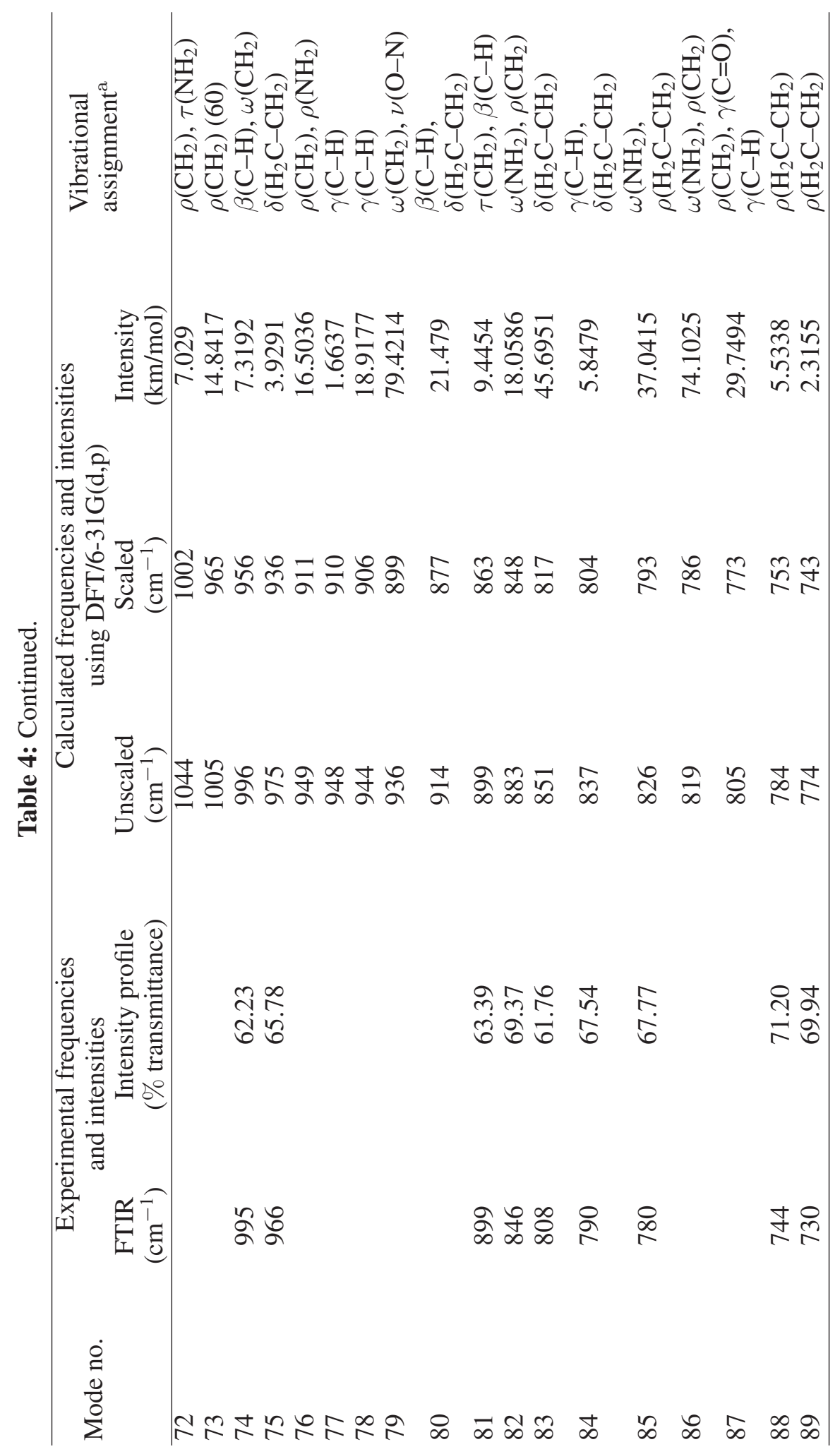




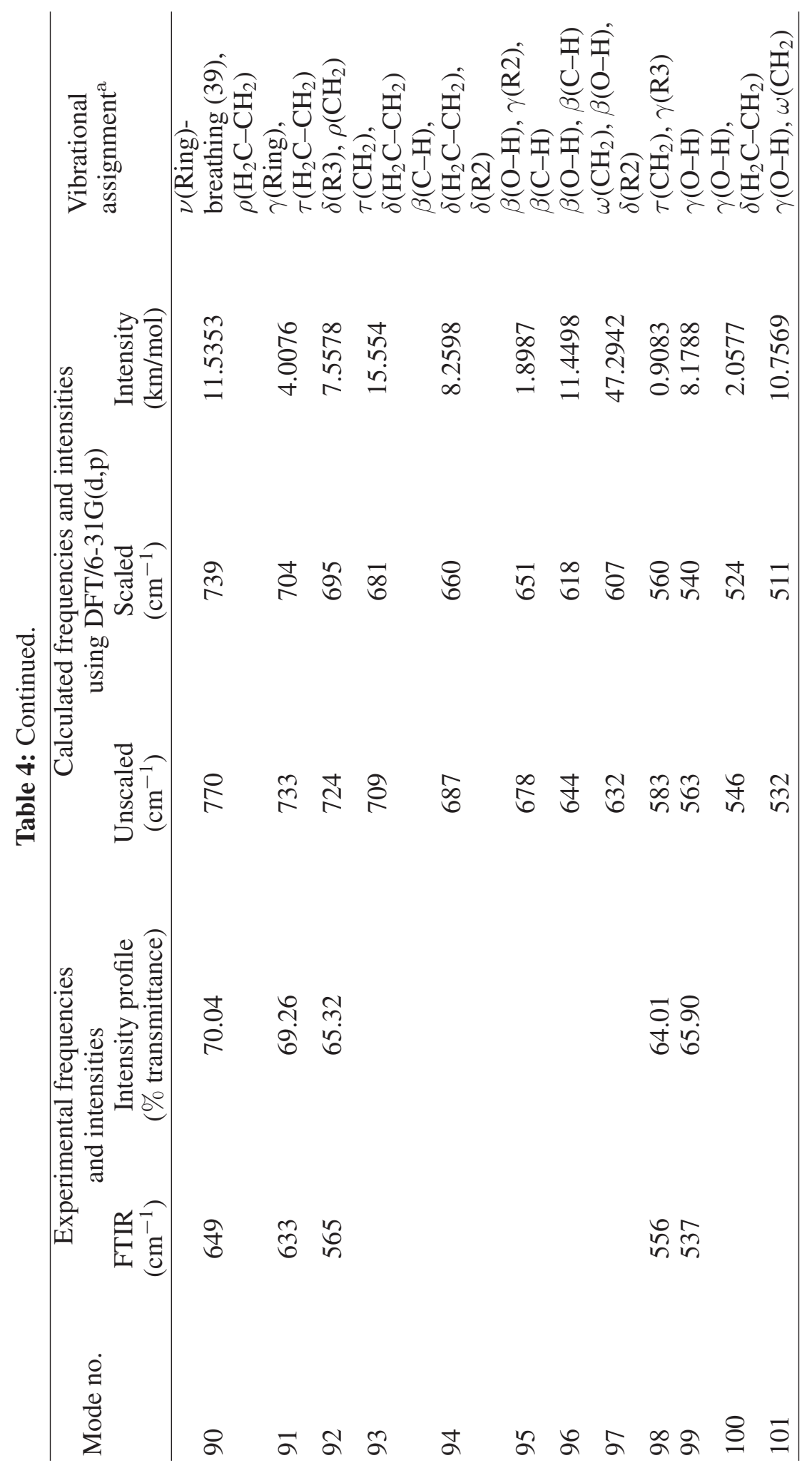




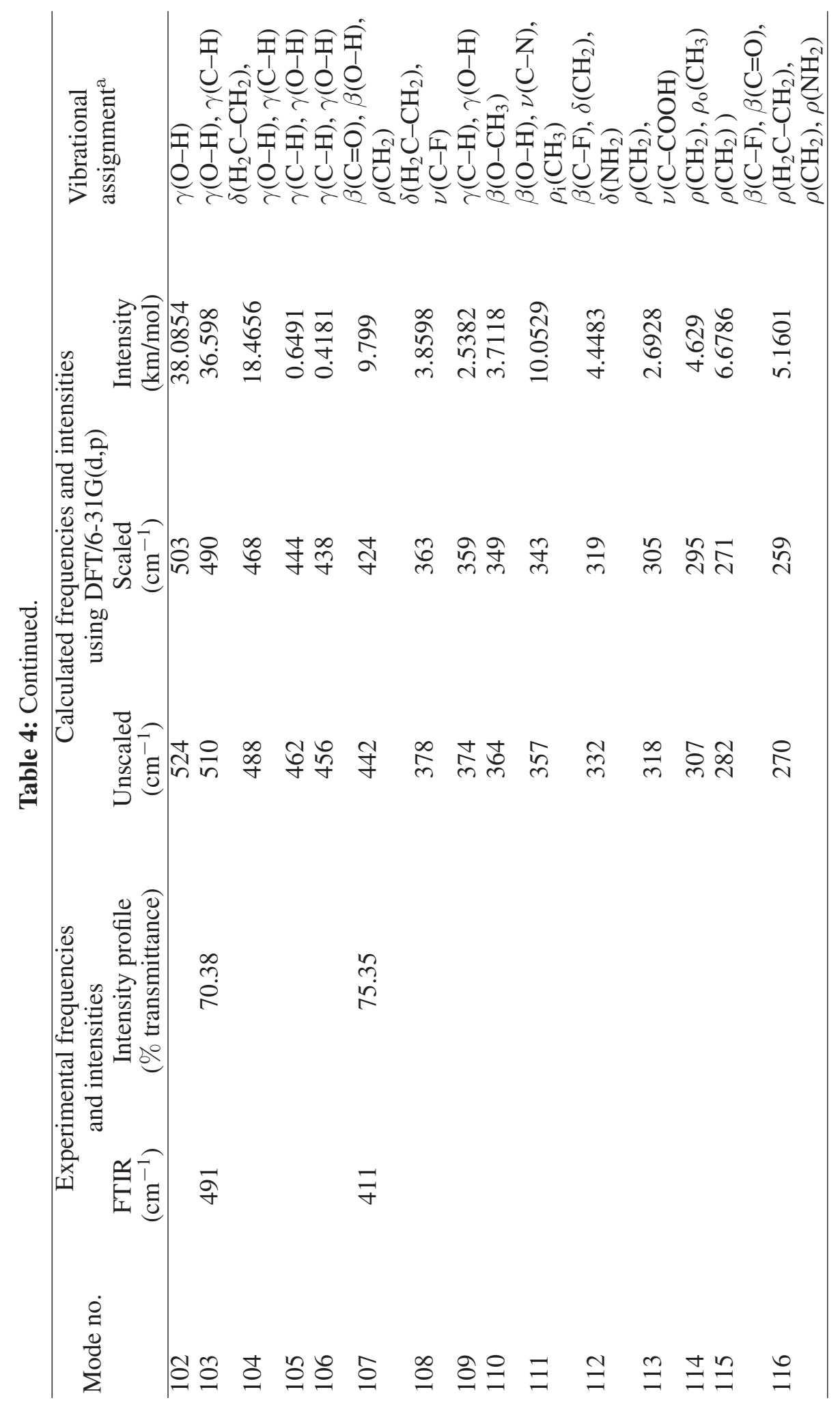




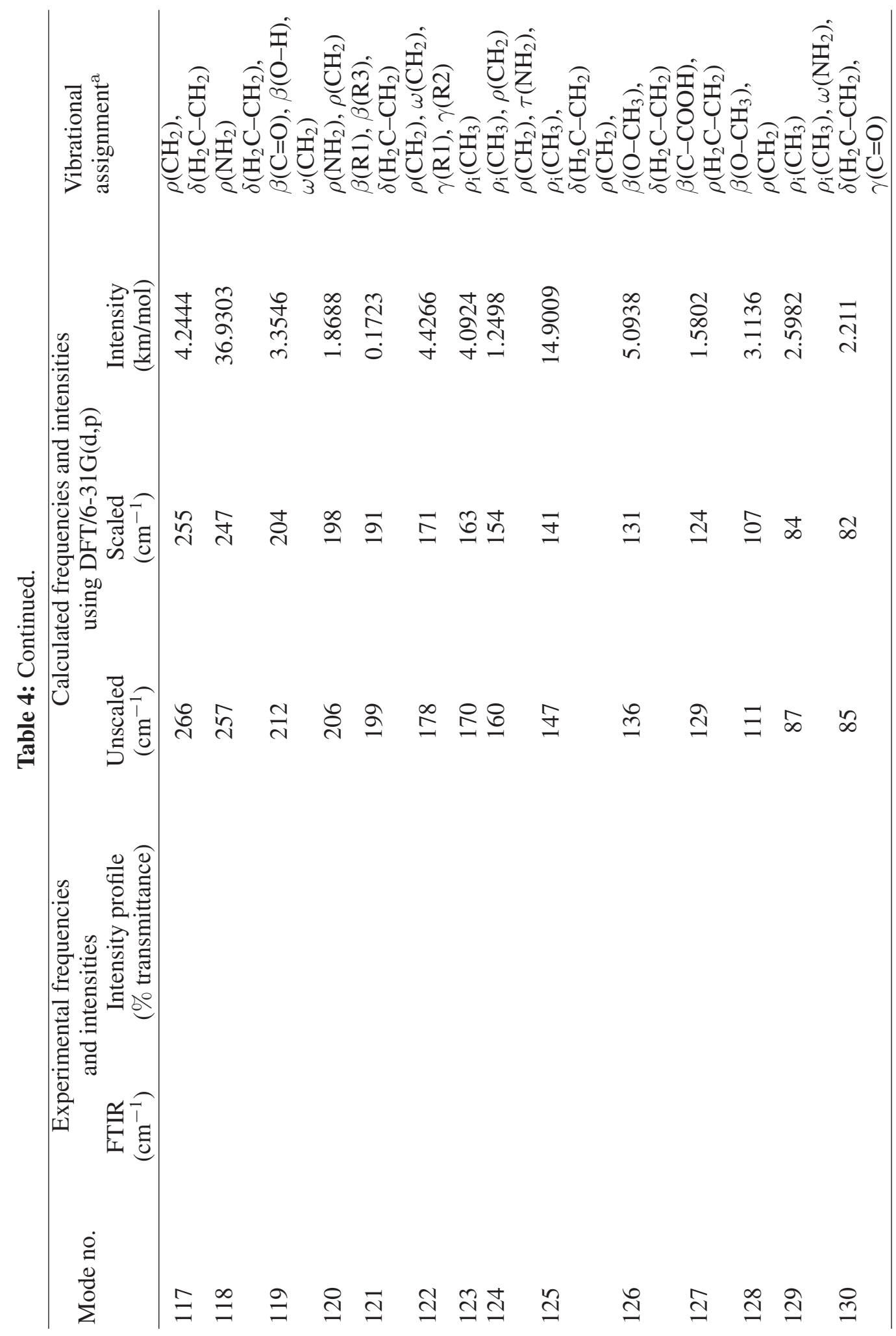




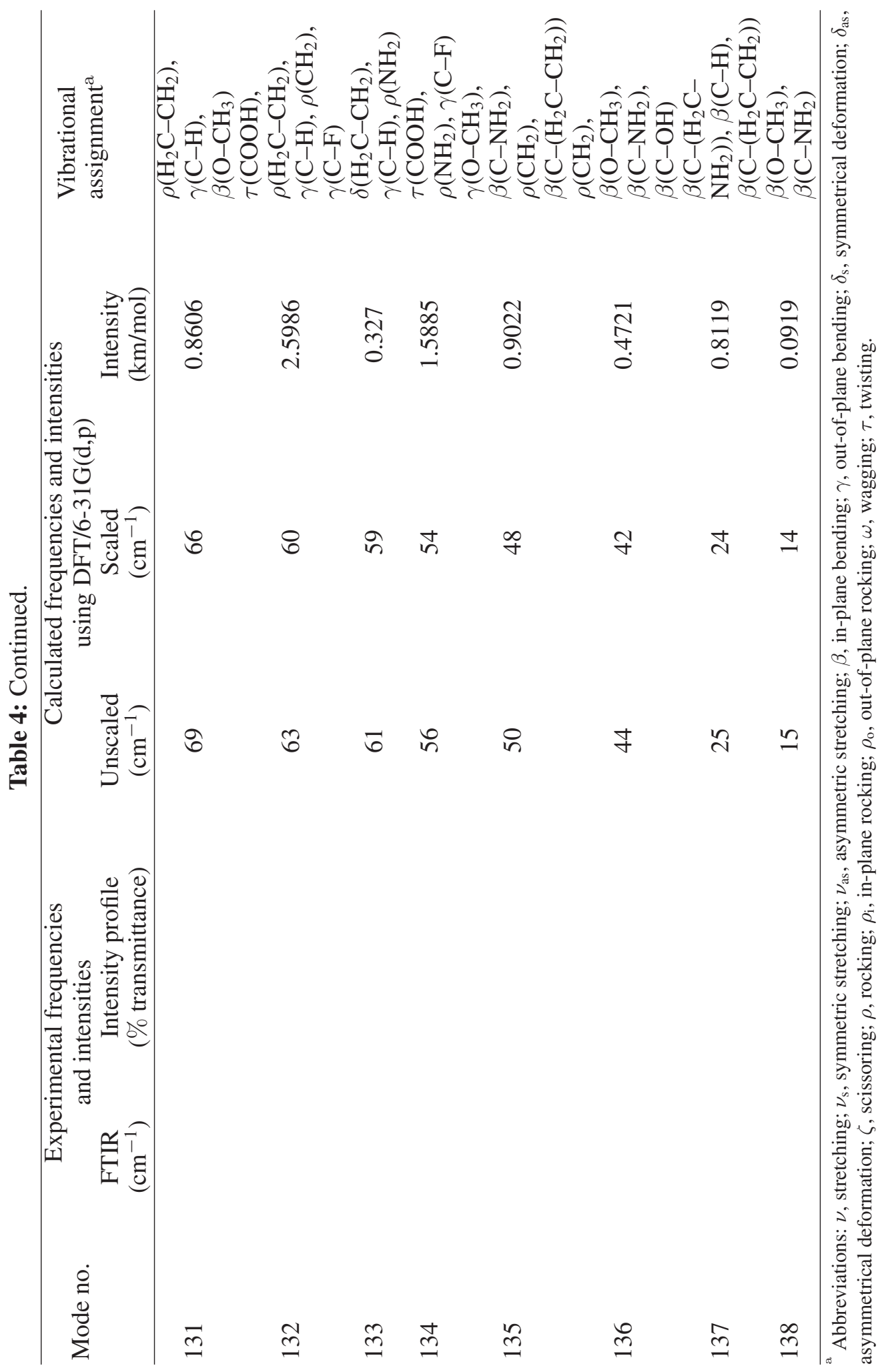


The twisting $(\tau)$ and rocking $(\rho)$ vibrations for both the functional groups are present mixed with other vibrations.

The other important functional group in gemifloxacin is the $-\mathrm{CH}_{3}$ group. There are nine modes of vibration of methyl group, which are distributed as follows: one symmetric stretching $\left(\nu_{\mathrm{s}}\right)$, two antisymmetric stretching $\left(\nu_{\mathrm{as}}\right)$, one symmetrical deformation $\left(\delta_{\mathrm{s}}\right)$, two asymmetrical deformation $\left(\delta_{\mathrm{as}}\right)$, one in-plane rocking $\left(\rho_{\mathrm{i}}\right)$, one out-of-plane rocking $\left(\rho_{\mathrm{o}}\right)$, and one twisting $(\tau)$ vibration modes [30]. The $\nu_{\mathrm{s}}\left(\mathrm{CH}_{3}\right)$ and $\nu_{\mathrm{as}}\left(\mathrm{CH}_{3}\right)$ vibrations, are present in higher frequency modes as pure vibrations, and the other vibrations are mixed with other vibrations. The $\mathrm{H}_{2} \mathrm{C}-\mathrm{CH}_{2}$ functional group which is attached to the $\mathrm{C}_{11}$ atom in gemifloxacin has unique vibrational fingerprints. It shows a number of vibrations, and these are distributed throughout the spectrum.

In gemifloxacin, a very important vibration corresponds to the modes involving the vibrations of the ring atoms. For the purpose of easing the analysis, we have classified the structure of gemifloxacin into three rings R1, R2, and R3 as shown in Figure 1. The ring stretching vibrations $\nu$ (Ring) are complicated combinations of stretchings of $\mathrm{C}-\mathrm{N}, \mathrm{C}=\mathrm{C}$, and $\mathrm{C}-\mathrm{C}$ bonds. The most important ring stretching vibration is the ring breathing vibration at mode 90 . In this mode, all bonds of the rings appear to stretch and contract in-phase with each other [33]. In the experimental infrared spectrum of gemifloxacin, this mode appears at $649 \mathrm{~cm}^{-1}$. Other ring vibration modes present a mixed profile.

\section{Conclusion}

In the present work we have calculated the geometric parameters, vibrational frequencies, frontier molecular orbitals, molecular electrostatic potential contours, and surfaces and the nonlinear optical properties of gemifloxacin using DFT/B3LYP method. Optimized geometry clearly shows that the skeleton of the title molecule is nonplanar. The higher frontier orbital gap of $4.30 \mathrm{eV}$ shows that gemifloxacin has high kinetic stability and can be termed as hard molecule. However, the higher value of dipole moment shows that gemifloxacin molecule is highly polar. Nonlinear optical behavior of title molecule was investigated by the determination of the dipole moment, the polarizability, and the first static hyperpolarizability using density functional B3LYP method. In general, a good agreement between experimental and calculated normal modes of vibrations has been observed. The molecular electrostatic potential contours and surfaces have also been drawn to explain the activity of gemifloxacin molecule. The present quantum chemical study may further play an important role in understanding of the structure, activity, and dynamics of the molecule.

\section{Acknowledgment}

One of the authors (Shamoon Ahmad Siddiqui) is thankful to the Deanship of Scientific Research for Grant no.: NU 16/11, Najran University, Najran, Kingdom of Saudi Arabia for financial support.

\section{References}

[1] G. Yague, J. E. Morris, X. S. Pan, K. A. Gould, and L. M. Fisher, "Cleavable-complex formation by wild-type and quinolone-resistant Streptococcus pneumoniae type II topoisomerases mediated by 
gemifloxacin and other fluoroquinolones," Antimicrobial Agents and Chemotherapy, vol. 46, no. 2, pp. 413-419, 2002.

[2] J. Ruiz, F. Marco, J. M. Sierra et al., "In vitro activity of gemifloxacin against clinical isolates of Neisseria gonorrhoeae with and without mutations in the gyrA gene," International Journal of Antimicrobial Agents, vol. 22, no. 1, pp. 73-76, 2003.

[3] M. Alkorta, M. J. Giménez, D. Vicente, L. Aguilar, and E. Pérez-Trallero, "In vivo activity of gemifloxacin, moxifloxacin and levofloxacin against pneumococci with gyrA and parC point mutations in a sepsis mouse model measured with the all or nothing mortality end-point," International Journal of Antimicrobial Agents, vol. 25, no. 2, pp. 163-167, 2005.

[4] P. Imming, C. Sinning, and A. Meyer, "Drugs, their targets and the nature and number of drug targets," Nature Reviews Drug Discovery, vol. 5, no. 10, pp. 821-834, 2006.

[5] R. D. Fleischmann, M. D. Adams, O. White et al., "Whose-genome random sequencing and assembly of Haemophilus influenzae Rd," Science, vol. 269, no. 5223, pp. 496-521, 1995.

[6] J. P. Overington, B. Al-Lazikani, and A. L. Hopkins, "How many drug targets are there?" Nature Reviews Drug Discovery, vol. 5, no. 12, pp. 993-996, 2006.

[7] K. L. LaPlante, M. J. Rybak, B. Tsuji, T. P. Lodise, and G. W. Kaatz, "Fluoroquinolone resistance in Streptococcus pneumoniae: area under the concentration-time curve/MIC ratio and resistance development with gatifloxacin, gemifloxacin, levofloxacin, and moxifloxacin," Antimicrobial Agents and Chemotherapy, vol. 51, no. 4, pp. 1315-1320, 2007.

[8] W. Kohn and L. J. Sham, "Self-consistent equations including exchange and correlation effects," vol. 140, pp. A1133-A1138, 1965.

[9] A. D. Becke, "Density-functional thermochemistry. III. The role of exact exchange," The Journal of Chemical Physics, vol. 98, no. 7, pp. 5648-5652, 1993.

[10] C. Lee, W. Yang, and R. G. Parr, "Development of the Colle-Salvetti correlation-energy formula into a functional of the electron density," Physical Review B, vol. 37, no. 2, pp. 785-789, 1988.

[11] B. Miehlich, A. Savin, H. Stoll, and H. Preuss, "Results obtained with the correlation energy density functionals of becke and Lee, Yang and Parr," Chemical Physics Letters, vol. 157, no. 3, pp. 200206, 1989.

[12] M. J. Frisch, G. W. Trucks, H. B. Schlegel et al., Gaussian 03, Revision A.1, Gaussian, Pittsburgh, $\mathrm{Pa}, \mathrm{USA}, 2003$.

[13] A. P. Scott and L. Radom, "Harmonic vibrational frequencies: an evaluation of hartree-fock, møllerplesset, quadratic configuration interaction, density functional theory, and semiempirical scale factors," Journal of Physical Chemistry, vol. 100, no. 41, pp. 16502-16513, 1996.

[14] P. Pulay, G. Fogarasi, G. Pongor, J. E. Boggs, and A. Vargha, "Combination of theoretical ab initio and experimental information to obtain reliable harmonic force constants. Scaled Quantum Mechanical (SQM) force fields for glyoxal, acrolein, butadiene, formaldehyde, and ethylene," Journal of the American Chemical Society, vol. 105, no. 24, pp. 7037-7047, 1983.

[15] A. Frisch, R. D. Dennington II, T. D. Keith et al., Gauss View version 4.1 User Manual, Gaussian, Wallingford, Conn, USA, 2007.

[16] M. H. Jamroz, Vibrational Energy Distribution Analysis: VEDA 4 Program, Warsaw, 2004.

[17] D. Sajan, H. J. Ravindra, N. Misra, and I. H. Joe, "Intramolecular charge transfer and hydrogen bonding interactions of nonlinear optical material N-benzoyl glycine: vibrational spectral study," Vibrational Spectroscopy, vol. 54, no. 1, pp. 72-80, 2010.

[18] V. Mukherjee, N. P. Singh, and R. A. Yadav, "FTIR and Raman spectra, DFT and SQMFF calculations for geometrical interpretation and vibrational analysis of some trifluorobenzoic acid dimers," Vibrational Spectroscopy, vol. 52, no. 2, pp. 163-172, 2010.

[19] O. Prasad, L. Sinha, N. Misra, V. Narayan, N. Kumar, and J. Pathak, "Molecular structure and vibrational study on 2,3-dihydro-1H-indene and its derivative $1 \mathrm{H}$-indene-1,3(2H)-dione by density functional theory calculations," Journal of Molecular Structure, vol. 940, no. 1-3, pp. 82-86, 2010. 
[20] A. D. Buckingham, "Permanent and induced molecular moments and long-range intermolecular forces," Advances in Chemical Physics, vol. 12, pp. 107-142, 1967.

[21] D. R. Kanis, M. A. Ratner, and T. J. Marks, "Design and construction of molecular assemblies with large second-order optical nonlinearities. Quantum chemical aspects," Chemical Reviews, vol. 94, no. 1, pp. 195-242, 1994.

[22] G. Maroulis, "Static hyperpolarizability of the water dimer and the interaction hyperpolarizability of two water molecules," Journal of Chemical Physics, vol. 113, no. 5, pp. 1813-1820, 2000.

[23] I. Fleming, Frontier Orbitals and Organic Chemical Reactions, John Wiley \& Sons, New York, NY, USA, 1976.

[24] J. S. Murray and K. Sen, Molecular Electrostatic Potentials, Concepts and Applications, Elsevier, Amsterdam, The Netherlands, 1996.

[25] I. Alkorta and J. J. Perez, "Molecular polarization potential maps of the nucleic acid bases," International Journal of Quantum Chemistry, vol. 57, no. 1, pp. 123-135, 1996.

[26] E. Scrocco and J. Tomasi, Advances in Quantum Chemistry, Academic Press, New York, NY, USA, 1978.

[27] F. J. Luque, M. Orozco, P. K. Bhadane, and S. R. Gadre, "SCRF calculation of the effect of hydration on the topology of the molecular electrostatic potential," Journal of Physical Chemistry, vol. 97, no. 37, pp. 9380-9384, 1993.

[28] J. Sponer and P. Hobza, "The wiener polynomial of a graph," International Journal of Quantum Chemistry, vol. 60, no. 5, pp. 959-970, 1996.

[29] M. A. Palafox, G. Tardajos, A. Guerrero-Martínez et al., "FT-IR, FT-Raman spectra, density functional computations of the vibrational spectra and molecular geometry of biomolecule 5aminouracil," Chemical Physics, vol. 340, no. 1-3, pp. 17-31, 2007.

[30] J. S. Singh, "FTIR and Raman spectra and fundamental frequencies of biomolecule: 5-Methyluracil (thymine)," Journal of Molecular Structure, vol. 876, no. 1-3, pp. 127-133, 2008.

[31] C. P. Beetz Jr. and G. Ascarelli, "The low frequency vibrations of pyrimidine and purine bases," Spectrochimica Acta, vol. 36, no. 3, pp. 299-313, 1980.

[32] J. Bandekar and G. Zundel, "The role of CO transition dipole-dipole coupling interaction in uracil," Spectrochimica Acta, vol. 39, no. 4, pp. 337-341, 1983.

[33] T. Rasheed and S. Ahmad, "Computational studies of vibrational spectra and molecular properties of 6-methyluracil using HF, DFT and MP2 methods," Indian Journal of Physics, vol. 85, no. 2, pp. 239-260, 2011. 


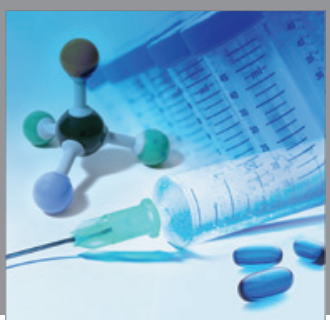

International Journal of

Medicinal Chemistry

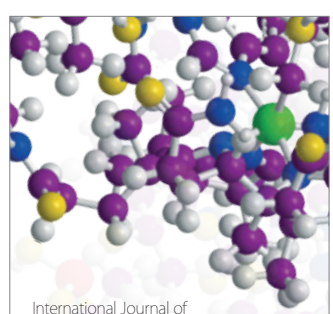

Carbohydrate Chemistry

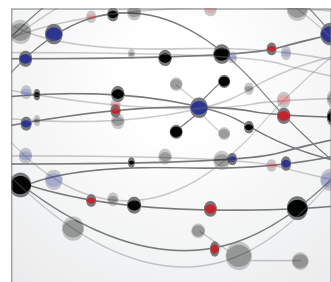

The Scientific World Journal
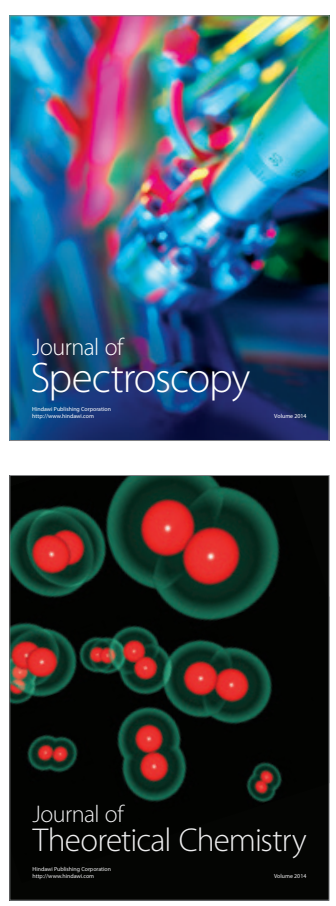
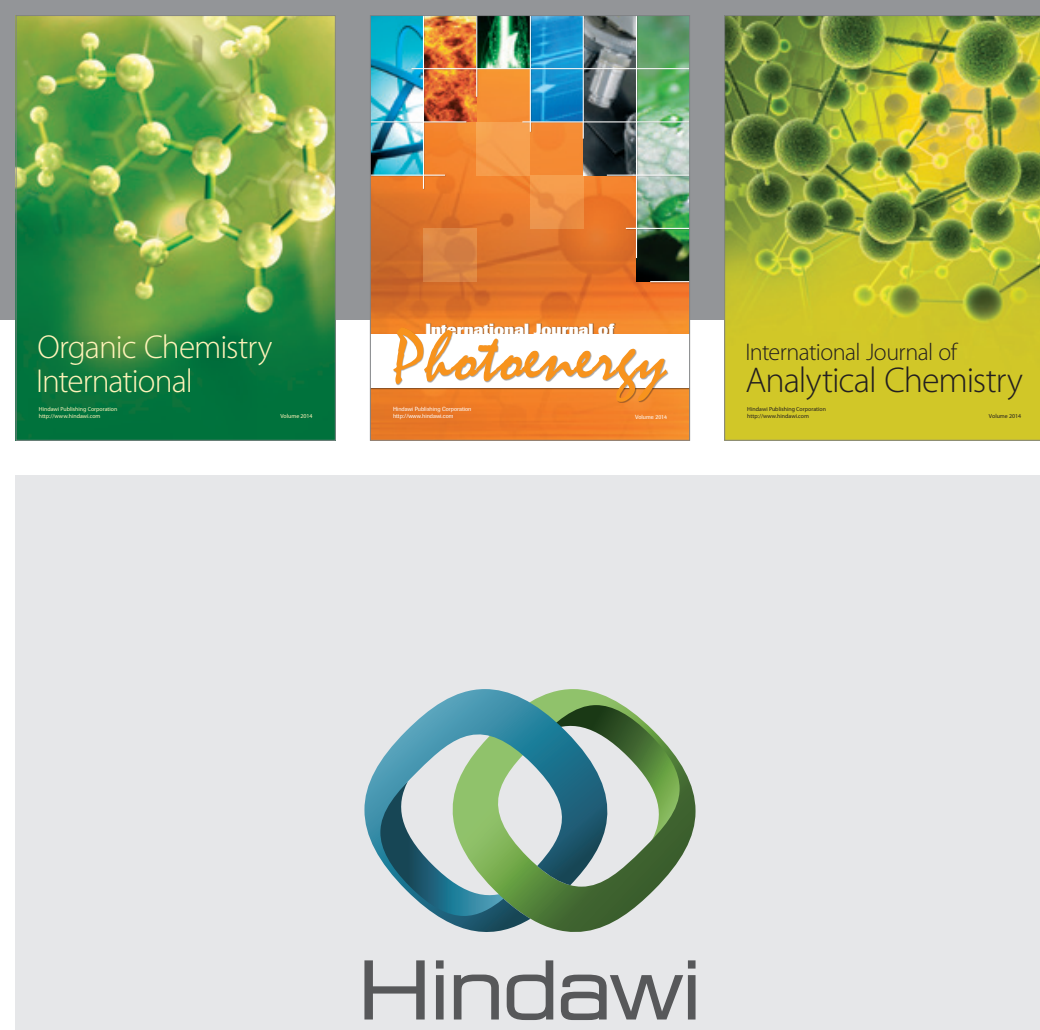

Submit your manuscripts at

http://www.hindawi.com
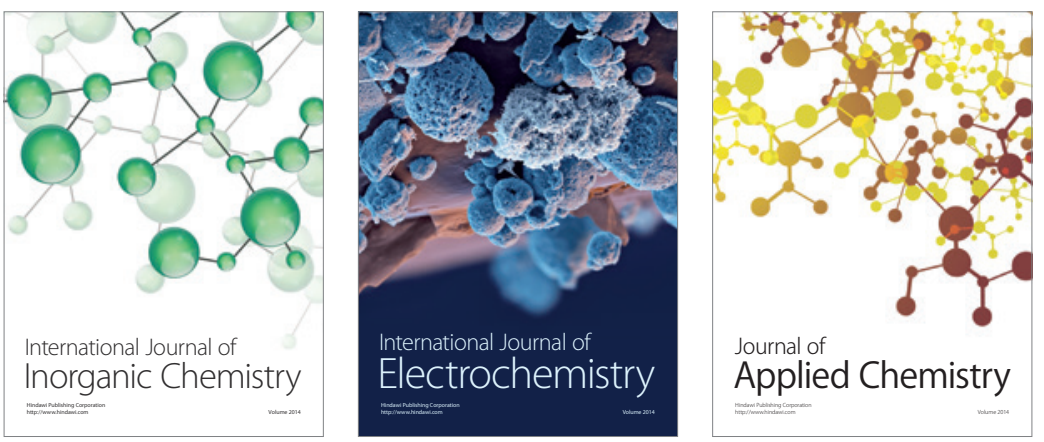

Journal of

Applied Chemistry
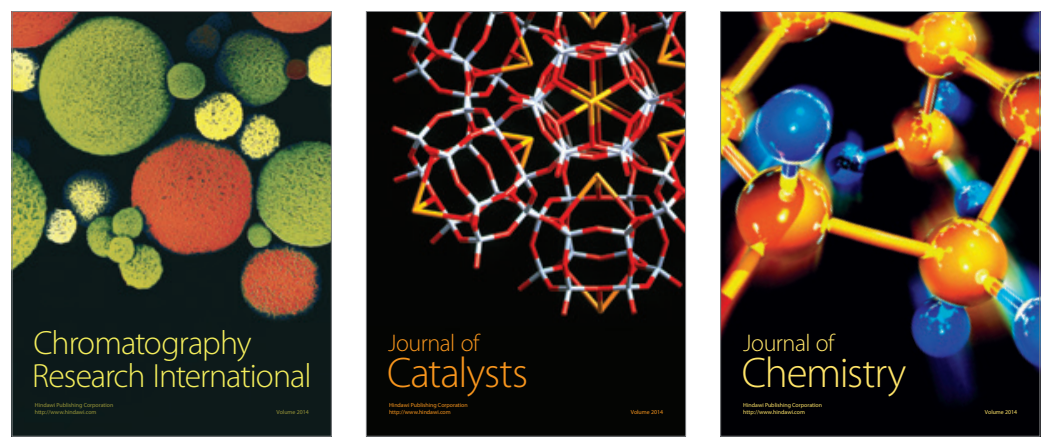
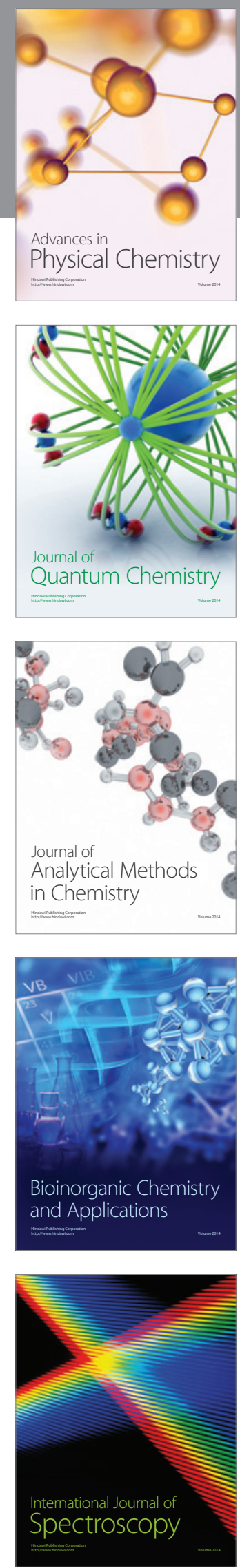